\title{
Analysis of Modular Architecture and Trade-in
}

\author{
Zican Luo ${ }^{1,2, a}$ and Houcai Shen ${ }^{1, a,{ }^{*}}$ \\ ${ }^{1}$ School of Management \& Engineering, Nanjing University, Nanjing, 210093, China \\ ${ }^{2}$ Business school, Hunan University of Technology, Zhuzhou, 412007, China \\ altcas@hotmail.com \\ * The Corresponding author
}

Keywords: Modular Architecture; Pricing; Trade-in

\begin{abstract}
This paper studies the problem of modular architecture when the durable goods are sequential innovation and manufacturers adopt the trade-in policy. It is assumed that consumer preferences for product quality are uniformly heterogeneous. In order to expand sales, the manufacturers used the trade-in policy to buy back the old modules. Through the study found that, The manufacturer's profit is commonly effect by upgrading quality loss and the second version improved module and the launch time of second version product and not the loss degree is low, the high quality of product must makes high profits. When the product is gradual improvement, the quality of the second version product is not high, the attraction of high-end consumers is insufficient, so these consumers will choose to buy the first version of product and then upgrade product. if the product design can not make the loss degree low enough, the manufacturer should not put much resources into the improvement of the performance module in the future to improve the quality.
\end{abstract}

\section{Introduction}

Due to the resistance of products (Durable Product) the cross term service life: the service life of the product is longer than two times sales interval, thus inhibiting the new product sales, durable goods led to the time inconsistency problem Coase[1]. Manufacturers in order to enhance sales of new products, often improve product quality, reduce prices or marketing means to stimulate sales of new products, thereby increasing profits. Among them, the Trade-in is used by many durable goods manufacturers. For example, the automotive industry, household appliances, computers, and consumer electronics in recent years. The trade-in can reduce the cost of the next purchase and stimulate the sales of the next generation.

In this paper, we will focus on the impact of the trade-in strategy on the modular product architecture, under what conditions, select the production of modular architecture products. The modular architecture are made up of two modules: one is Stable Module, and the other is Improving Module. The modular architecture of the product can be modular upgrade (Modular Upgradable) stable module does not change, only to improve the performance of the module to upgrade and replacement, and there is a loss of quality upgrade. This modular upgrade exists in many industries, such as computer, semiconductor, IBM, Intel, and AMD machines[2].

When we study that the product is Rapid Sequential Innovation, product pricing, we put the trade-in's the price discount rate, new product launch time and improve the quality of height together, then study the influence of these factors on product design and architecture. The remainder of the paper consists of the following parts: the second part, summing up the trade-in and modular architecture of the literature; the third part, put forward the model assumptions and models; the fourth part, analysis model; the fifth part, numerical analysis; the sixth part, managerial insights and future research direction.

\section{Literature Review}

Reviewing two parts of related literature: (1) Trade-in; (2) Modular Architecture. 
Trade-in. There are three reasons why firm uses the trade-in: first, reducing the cost which consumer supplants the old product for new product; second, closing the secondary market (shift adverse selection); last, increasing the frequency of consumer purchase.

Another point is that pricing new and old product and whether to close secondary market are researched in pricing and consumer demand model in literature. Ackere and Reyniers [3] studied two period monopoly model which the firm provides two discount pattern to consumer in the second period: one is trade-in, another is Introductory offers to consumer who buy new product. Fudenberg and Tirole [4] studied that the firm open or close the secondary market in what conditions in the two stages model that durable product's quality continuously is improved. Rao et al. [5] found that the profit that the firm obtains in using the strategy of trade-in is more than the firm open the secondary market that adverse selection's factor in it. Ray, Boyaci and Aras [6] compared three kinds of pricing: Uniform Price, Age-Independent Price Differentiation and Age-dependent Price Differentiation. Authors get conclusion that the firm should choose what kind of pricing in what conditions in numerical experiment. Busse and Silva-Risso [7] found that the margin profit of new car and the margin profit of trade-in have common negative correlation after they empirically study the American auto retailer's data that from 2005 to 2007. Huang et al. [8] researched the problem that the auto manufacturer and retailer how to deal with the policy of trade-in which the government put forward.

Modular Architecture. Baldwin and Clark [9] discussed the evolutionary path of product architecture of electronics and automotive industry for decades from integrated to modular architecture. Mikkola [10] pointed out four factors which influence performance of modular product: Components, Interfaces, Degree of Coupling and Substitutability. When product is Rapid Sequential Innovation, Kornish [11] found that market will be equilibrium, if monopoly doesn't use Upgrade Pricing.

Ulrich [12] considered two kinds of product performance: Global Performance is that product performance is decided by all components; Local Performance is that product performance is decided by one or several components. Ethiraj et al. [13] researched three product architecture: Modular, Nearly Modular, Nonmodular. In the three design architectures, what advantage and disadvantage of product innovation and imitation, respectively.

Krishnan and Ramachandran [14] found that product architecture has Design Inconsistency problem: the first version product's architecture isn't same as the second version product's. The authors found that the problem can't be solved by promising the second version product's price, only be solved by setting threshold price for the first version product. Ramachandran and Krishnan [2] researched the problem that in the three situations: Proprietary Modular Upgradable Systems, Nonproprietary Modular Upgradable Systems and Proprietary Integral Systems, the speed of improving and the timing of new product introduction influence product architecture. The authors found that the speed of innovation is faster in modular architecture. Ji, Gunasekaran and Lv [15] put the factor that is the cost of service in the process of using into the model.

Ülkü et al. [16] studied the problem that consumers have the value deviation of product in aspect of product architecture in empirical method. Yin et al. [17] compared three product architecture which is modular, integrated and hybrid in Global Performance. The author found that the integrated architecture is better than modular architecture, if Global Performance is high.

Glimstedt [18] reviewed the history which Ericsson outsourced technology from 1980 to 2010 and analyzed cyclical phenomenon between Outsourcing and Re-integration in this period. Ülkü et al. [19] studied the product architecture in the supply chain. Nepal et al. [20] used Multi-objective Optimization model to research how the firm design the product architecture in the supply chain. Feng and Zhang [21] researched the Two-stage Modular Assembly System that the supplier purchased two kinds of components to integrate one module, then sold it to manufacturer. Sanchez [22] proposed several new method and problem, when it combines product architecture and marketing.

So, there're few papers that research problem about combine the trade-in and modular architecture. This paper is the first one to study the subject. 


\section{The Problem Description and the Model}

On the assumption, there is a monopoly manufacturer in the market. In the finite period of selling, the manufacturer develops two version of product: the first version of product is launched in the first period, the improved product is launched in the second period by manufacturer. The product is not disruptive innovation products, but is sequential innovation products. The quality of product can be improved by modular upgrading which a module in product can be exchange from improved module. The quality is denoted by $q_{t}$, where $t \in\{1,2\}$ represents the period. So, the first version product's quality is denoted by $q_{1}$, the second version product's quality is denoted by $q_{2}$, and $q_{1}<q_{2}$. The product is durable product that the service life of product is longer than time interval of two sales. The consumer who bought the first version product can continue to use the first version product, when the manufacturer launches the second version product.

Design Assumption. The product is composed of two modules: the one is stable module, the another is improving module. There is no overlap between these two modules. The product can be function when these two modules make up the product. So, there are two product architectures: modular architecture and integrated architecture. The whole product need to be replaced to new product, when the integral architecture product upgrades. The product's improving module need to be upgrade and stable module don't be replaced, when the product is modular architecture. The quality of stable module is denoted by $q_{t s}$, and the quality of improving module is denoted by $q_{t i}$. Their quality is same [19].

$$
q_{t}=q_{t s}+q_{t i}
$$

So, the first version product's quality is $q_{1}=q_{1 s}+q_{1 i}$, the second version product's quality is $q_{2}=q_{2 s}+q_{2 i}$. Because product is durable product, when upgrading product is modular upgradable, the first version product's stable module is still can be used which make up the second version product, and $0<q_{2 s}<q_{1 s}$. The improving module has expression: $0<q_{1 i}<q_{2 i}$. The different point is that there is loss of quality because the interface of the old stable module and new improving module isn't smooth, when the product is modular upgradable. The loss of quality is denoted by $\alpha$, where $\alpha \in[0,1)$ [2]. $\alpha=0$ expresses that the modular upgradable doesn't bring about loss of quality to new modular product. In the second period, the consumer who bought the first version product upgrades the old product through modular upgradable, then the quality of upgraded product is:

$$
q_{2}^{\alpha}=(1-\alpha)\left(q_{1 s}^{\prime}+q_{2 i}\right)
$$

Where $q_{1 s}^{\prime}$ is expressed that the surplus of stable module's quality after the first period, and $q_{2}>q_{2}^{\alpha}>q_{1}$.

Trade-in Decision. The consumer who bought the first version product can use the money that the manufacturer trades in the first version product to deduct the price of the second version product. The deducted price is which consumer reality pay for the second version product. When the product's architecture is modular architecture, the first and second version product's price are denoted by $p_{1 m}$ and $p_{2 m}$, respectively. The consumer who bought the first version product modularly upgrades product through trade-in, then the price of second version improving module is $p_{3 m}$.

Consumer's Decisions. Consumer is strategic consumer who can predicts the price of new product accord to the new product's information (For example, product's quality) which access it through all sorts of channel before launching new product. In the two periods, consumer realizes own maximize surplus utility through comparing current surplus utility with future surplus utility. The consumer's Willingness to Pay about quality is denoted by $\theta$, where is uniformly distributed on $[0,1]$. When the quality of product is $q_{t}$ and the price of product is $p_{t}$, the consumer's surplus utility is

$$
w\left(q_{t}, p_{t}, \theta\right)=q_{t} \theta-p_{t}
$$

When $w>0$, the consumer buys the product. In every period, the discount factor of consumer 
and manufacturer is same $\delta$, where $\delta \in(0,1)$. The consumer's surplus utility who bought the first version product is $(1-\delta) q_{1} \theta-p_{1 m}$, in the first period, where $(1-\delta) q_{1} \theta$ expresses consumer's utility. The consumer's surplus utility which is acquire by using the second version product is equivalent to $\delta\left(q_{2} \theta-p_{2 m}\right)$, in the first period. After consumer bought the first version product, the consumer's surplus utility which is acquire by using the modular upgradable product through trade-in is:

$$
\left((1-\delta) q_{1} \theta-p_{1 m}\right)+\delta\left((1-\alpha)\left(q_{1 s}^{\prime}+q_{2 i}\right) \theta-p_{3 m}\right)
$$

When the product is modular architecture.

In the first period, consumer can only buy the first version product. There are three kinds of consumer to buy product: first, no matter what consumer upgrades product or not, as long as his surplus utility is more than zero and the surplus utility that obtain through using the second version product, the consumer will buy, assume,

$$
\begin{aligned}
& q_{1} \theta-p_{1 m} \geq 0 \\
& q_{1} \theta-p_{1 m} \geq \delta\left(q_{2} \theta-p_{1 m}\right)
\end{aligned}
$$

Second, although the consumer obtains the surplus utility which using the first version product is less than zero, the two phase of the total surplus utility which modularly upgrades product in the second period is more than the surplus utility which doesn't upgrade product,

$$
\begin{aligned}
& q_{1} \theta-p_{1 m} \leq 0 \\
& \left((1-\delta) q_{1} \theta-p_{1 m}\right)+\delta\left((1-\alpha)\left(q_{1 s}^{\prime}+q_{2 i}\right) \theta-p_{3 m}\right) \geq q_{1} \theta-p_{1 m}
\end{aligned}
$$

Last, although the surplus utility which consumer acquires through using the first version product is less than which consumer acquires through using the second version product, the two phase of total surplus utility which consumer acquires through using the first version product and then upgradable product is more than which consumer acquires through using the second version product,

$$
\begin{aligned}
& q_{1} \theta-p_{1 m} \leq \delta\left(q_{2} \theta-p_{1 m}\right) \\
& \left((1-\delta) q_{1} \theta-p_{1 m}\right)+\delta\left((1-\alpha)\left(q_{1 s}^{\prime}+q_{2 i}\right) \theta-p_{3 m}\right) \geq \delta\left(q_{2} \theta-p_{1 m}\right)
\end{aligned}
$$

In the second period, the manufacturer sells two kinds of product, one is the second version product, another is the second version improving module. The condition which consumer buy the second version product is that surplus utility isn't less than zero,

$$
q_{2} \theta-p_{1 m} \geq 0
$$

And isn't less than which consumer acquires surplus utility through using the first version product,

$$
q_{1} \theta-p_{1 m} \leq \delta\left(q_{2} \theta-p_{1 m}\right)
$$

And isn't less than which consumer acquires surplus utility through using the first version product and modular upgradable product,

$$
\left((1-\delta) q_{1} \theta-p_{1 m}\right)+\delta\left((1-\alpha)\left(q_{1 s}^{\prime}+q_{2 i}\right) \theta-p_{3 m}\right) \leq \delta\left(q_{2} \theta-p_{1 m}\right)
$$

Another kind of consumer who buy the first version product can modularly upgrades product in the second period. There are three kinds about the part of consumer: one kind, the consumer who bought the first version product modularly upgrades product because of higher surplus utility. The conditions are Eq.5, Eq. 6 and Eq.8.

Second kind, in the condition, the surplus utility which acquire through using the first version product is less than zero, the total surplus utility is more than doesn't modularly upgrade first version product. The conditions are Eq.7 and Eq.8.

Last kind, the surplus utility which consumer acquires through using the second version product isn't less than which consumer acquires surplus utility through using the first version product, and 
the two phase of total surplus utility which consumer acquires through using the first version product and then upgradable product is more than which consumer acquires through using the second version product. The conditions are Eq.9 and Eq.10.

\section{Model Analysis}

To consider the manufacturer's profit maximization when the manufacturer determines the product's architecture and price. When the product is modular architecture, then the manufacturer's second period optimization problem is given by Eq.14, where the demands $D_{2}$ and $D_{2 T}$ are denoted by the second version product of demand and the trade-in of quantity

$$
\begin{aligned}
& \Pi_{2 m}=\max _{p_{3 m}} p_{1 m} D_{2}+p_{3 m} D_{2 T} \\
& \text { s.t. } f_{i}\left(p_{1 m}, p_{3 m}\right) \geq 0 \quad(i=1,2, \ldots, m)
\end{aligned}
$$

In the first period, the firm sets its first-period price $p_{1}$ to maximize the net present value of its revenue stream from the two periods, where $D_{1}$ is denoted by the first version product's demand.

$$
\begin{aligned}
& \Pi_{m}=\max _{p_{1 m}} p_{1 m} D_{2}+\delta \Pi_{2 m}^{*} \\
& \text { s.t. } f_{j}\left(p_{1 m}, p_{3 m}\right) \geq 0 \quad(i=1,2, \ldots, n)
\end{aligned}
$$

There're two kinds of improvement module: rapid improvement $\delta q_{2} \geq q_{1}$ and gradual improvement $\delta q_{2} \leq q_{1}$. Every kind has two kinds: the discount quality of the second version product isn't lower than the discount quality of modular upgraded product and the discount quality of the second version product isn't higher than the discount quality of modular upgraded product. We'll find the optimal solution of every situation, then analyze the property of price function and demand function, at last choose the which kind of product architecture in which kind of situations. We'll use the Karush-Kuhn-Tucker Condition to solve the problem.

When the discount quality of the second version product isn't lower than the discount quality of modular upgraded product, there's only rapid improvement.

Proposition 1. When $\delta B \leq A, C<0, \eta_{1}=\eta_{2}=\eta_{3}=\eta_{4}=0$, the optimal price of the manufacturer is

$$
p_{1 m}^{*}=-\frac{2 B C \delta}{-4 C \delta+B}, p_{3 m}^{*}=-\frac{C\left(4 B \delta^{2}-2 B \delta-4 A C \delta+B\right)}{2 \delta(-4 C \delta+B)}
$$

Among $\eta_{j}, \mathrm{j} \in\{1,2,3,4\}$ is Lagrange multiplier, $A=q_{1}, B=q_{2}, \mathrm{C}=\delta q_{2}-(1-\delta) q_{1}-$ $\delta(1-\alpha)\left(q_{1 s}^{\prime}+q_{2 i}\right), \mathrm{D}=(1-\alpha)\left(q_{1 s}^{\prime}+q_{2 i}\right)$.

Proposition 2. When $\delta B \leq A, C<0, \eta_{1}=\eta_{2}=\eta_{3}=0, \eta_{4} \geq 0$ the optimal price of the manufacturer is

$$
\begin{aligned}
& p_{1 m}^{*}=\frac{B C(-B \delta+A-B+C)}{2\left(-B C \delta^{2}+A^{2}-2 A B+2 A C+B^{2}-2 B C+C^{2}\right)}, \\
& p_{3 m}^{*}=-\frac{p_{1 m}^{*}(-B \delta+A+C)}{B \delta},
\end{aligned}
$$

Among $\eta_{j}, \mathrm{j} \in\{1,2,3,4\}$ is Lagrange multiplier.

\section{Numerical Research}

For researching the impact which is the introduction time $(\delta)$ of the second version product and the quality of the second version improving module influence the manufacturer's choice of product architecture, we'll analyze these parameters' sensibility against manufacture's profit. The vertical axis is the manufacturer's profit and horizontal axis is the parameter in all of following figures.

The first, we'll research the situation of $\Pi_{12}$. When $\delta=0.2, \alpha=0.2$ and $q_{2 i} \in[3.2,3.5]$, the Fig. 1 shows how the $q_{2 i}$ influences the profit; When $\delta=0.2, q_{2 i}=3.2$ and $\alpha \in[0,0.3]$, the Fig. 2 shows how the $\alpha$ influences the profit. 


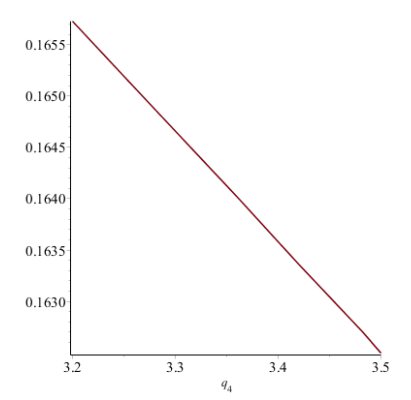

Figure 1. $q_{2 i}$ influences the profit

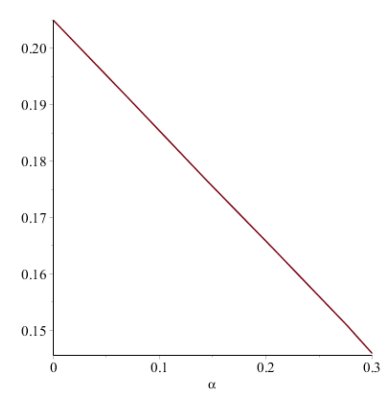

Figure 2. $\alpha$ influences the profit

Observation 1. When the quality of the second version improving module and the loss of quality are higher, the manufacturer's profit is lower.

The second, we'll research the situation of $\Pi_{23}$. When $\delta=0.2, \alpha=0.1$ and $q_{2 i} \in[0.8,2.5]$, the Fig. 3 shows how the $q_{2 i}$ influences the profit; When $\delta=0.2, \alpha=0.2$ and $q_{2 i} \in[1.8,3]$, the Fig. 4 shows how the $q_{2 i}$ influences the profit; When $\delta=0.2, q_{2 i}=2$ and $\alpha \in[0,0.5]$, the Fig. 5 shows how the $\alpha$ influences the profit.

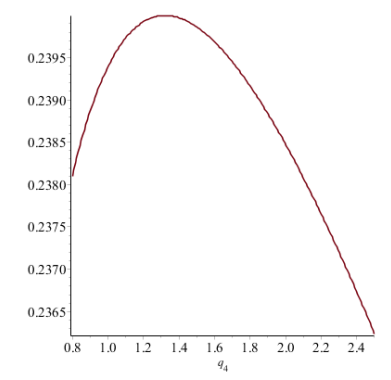

Figure 3. Finite $q_{2 i}$ influences the profit Figure 4. Finite $q_{2 i}$ influences the profit

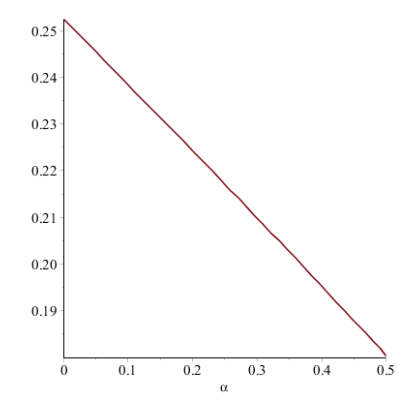

Figure 5. Finite $\alpha$ influences the profit

Observation 2. From the Fig. 3-5, whatever the second version product lunch time, when the loss of quality and the quality of the second version improving module are lower than the threshold, the manufacturer's profit increases along with higher of quality, when the quality of the second version improving module are higher than the threshold, the profit declines along with higher of quality; when the loss of quality is higher than the threshold, the profit declines along with higher of the quality of the second version improving module; the degree of the loss of quality is higher, then the profit is lower.

\section{Managerial Insights and Future Research Direction}

In this paper, we study the problem of modular architecture in the trade-in policy. Because of the technological innovation speed, durable goods manufacturers in response to consumer demand changes rapidly, at the same time to consolidate the existing market, to design a modular architecture and more products (such as mobile phone and home appliances). In this paper, we 
assume that the consumer's quality preference is uniform diversity, modular architecture is composed of two modules: the module of basic module and improvement module. In order to promote the sales of new products, manufacturers use trade-in policy from consumers repurchase generation improvement module or products, and give consumers certain subsidies to offset the purchase of new modules or the price of the product. The manufacturer does not generate costs in the manufacturing module, and the price of the first and second version is the same. As a result, the quality of the upgrade, the timing of the new product, the price and quality of the product have a bearing on the design of the product. What is different from Ramachandran[2] is that through our research found that:

The manufacturer's profit is commonly effect by upgrading quality loss and the second version improved module and the launch time of second version product and not the loss degree is low, the high quality of product must makes high profits. This is because the manufacturer needs to sell a new module while buying an old module, so the amount of the trade-in can be controlled only by determining the price of the second version module. When the product is gradual improvement, the quality of the second version product is not high, the attraction of high-end consumers is insufficient, so these consumers will choose to buy the first version of product and then upgrade product. Manufacturers in the product design process, it is necessary to minimize future upgrades when the quality of product losses. If this upgrade quality loss exceeds a certain threshold, with the second version improved module is improved, but the profit of the manufacturer in reducing losses; no more than this value, then the profit increases with the module of quality improvement to improve the performance of the second generation. Therefore, if the product design can not make the loss degree low enough, the manufacturer should not put much resources into the improvement of the performance module in the future to improve the quality.

This article focuses on the product sales process, the product recycling process is not considered in this article. What recycling channels should be chosen for the product to be recycled, whether the manufacturer is directly recycled or recycled through the retailer, does the different recycling channels affect the product design architecture? Also, this article assumes that the price of the first and second version product are the same. What would happen if the manufacturer adopted the dynamic pricing strategy? These issues will be the direction of future research.

\section{Acknowledgments}

This research is supported in part by the National Natural Science Foundation of China (No. 71671085)

\section{References}

[1] Coase, R. H. 1972. Durability and Monopoly. J. Law Economics. 15(1) 143-149.

[2] Ramachandran, K., V. Krishnan. 2008. Design architecture and introduction timing for rapidly improving industrial products. Manufacturing \& Service Operations Management 10(1) 149-171.

[3] Ackere, A. Van., D. J. Reyniers. 1995. trade-ins and introductory offers in a monopoly. The RAND Journal of Economics 26(1) 58-74.

[4] Fudenberg, D., J. Tirole. 1998. Upgrades, tradeins, and buybacks. The RAND Journal of Economics 29(2) 235-258.

[5] Rao, R. S., O. Narasimhan., G. John. 2009. Understanding the role of trade-ins in durable goods markets theory and evidence. Marketing Science 28(5) 950-967.

[6] Ray, S., T. Boyaci., N. Aras. 2005. Optimal prices and trade-in rebates for durable, remanufacturable products. Manufacturing \& Service Operations Management 7(3) 208-228.

[7] Busse, M. R., J. M. Silva-Risso. 2010. "One discriminatory rent" or "double jeopardy" : multicomponent negotiation for new car purchases. American Economic Review: Papers \& Proceedings 100 470-474.

[8] Huang, J., M.M. Leng., L.P. Liang., C. L. Luo. 2014. Qualifying for a government's scrappage 
program to stimulate consumers' trade-in transactions? Analysis of an automobile supply chain involving a manufacturer and a retailer. European Journal of Operational Research 239(2) 363376.

[9] Baldwin, C. Y., K. B. Clark. 1997. Managing in an age of modularity. Harvard Business Review 75(5) 84-93.

[10] Mikkola, J. H. 2006. Capturing the degree of modularity embedded in product architectures. Journal of Product Innovation Management 23(2) 128-146.

[11] Kornish, L. J. 2001. Pricing for a durable-goods monopolist under rapid sequential innovation. Management Science 47(11) 1552-1561.

[12] Ulrich, K.T. 1995. The role of product architecture in the manufacturing firms. Research Policy 24(3) 419-440.

[13] Ethiraj, S. K., D. Levinthal., R. R. Roy. 2008. The dual role of modularity innovation and imitation. Management Science 54(5) 939-955.

[14] Krishnan, V., K. Ramachandran. 2011. Integrated product architecture and pricing for managing sequential innovation. Management Science 57(11) 2040-2053.

[15] Ji, G. j., A. Gunasekaran., Y. Lv. 2015. The joint influence that service cost and product architecture exert on sequential innovation decisions. International Journal of Systems Science: Operations \& Logistics 2(2) 63-77.

[16] Ülkü, S., C. V. Dimofte., G. M. Schmidt. 2012. Consumer valuation of modularly upgradeable products. Management Science 58(9) 1761-1776.

[17] Yin, Y., I. Kaku., C. G. Liu. 2014. Product architecture, product development process, system integrator and product global performance. Production Planning \& Control 25(3) 203-219.

[18] Glimstedt, H., D. Bratt., M. P. Karlsson. 2010. The decision to make or buy a critical technology semiconductors at Ericsson, 1980-2010. Industrial and Corporate Change 19(2) 431-464.

[19] Ülkü, S., G. M. Schmidt. 2011. Matching product architecture and supply chain configuration. Production and Operations Management 20(1) 16-31.

[20] Nepal, B., L. Monplaisir., O. Famuyiwa. 2012. Matching product architecture with supply chain design. European Journal of Operational Research 216(2) 312-325.

[21]Feng, T., F. Zhang. 2014. The impact of modular assembly on supply chain efficiency. Production and Operations Management 23(1) 1985-2001.

[22] Sanchez, R. 1999. Modular Architectures in the Marketing Process. Journal of Marketing 63 92-111 (Special Issue). 